\title{
Human Impacts on Seals, Sea Lions, and Sea Otters: Integrating Archaeology and Ecology of the Northeast Pacific
}

Edited by Todd J. Braje and Torben C. Rick. 2011. University of California Press, Berkeley. Pp. 328. $\$ 65.00$ (hardcover). ISBN 9780520267268.

Reviewed by Ray Pierotti

Reviewer address: Ecology and Evolutionary Biology, University of Kansas. Lawrence, KS 66045-2106. pierotti@ku.edu

Received: February 8, 2013

Volume: 4:32-36

Published: March 7, 2013

(C) 2013 Society of Ethnobiology

Exploitation of wildlife populations by indigenous peoples typically involves exploitation of herbivores, such as bison, deer, or elk, or of fishes, such as salmon or halibut. It is unusual for hunting societies to focus much of their attention on top carnivores in an ecological system. This unusual state of affairs and its long term ecological consequences are the topic of this collection of papers.

In the marine environments along the Pacific Coast of North America and the Bering Sea, pinnipeds (seals, sea lions, and walrus) and sea otters are among the top predators. In addition, sea otters are considered to be a keystone predator responsible for structuring nearshore benthic communities. These species are the largest warm-blooded animals that come onshore, and are thus available for hunting by humans along these coasts. One reason that it is possible for humans to hunt predators is that marine food chains are very different than terrestrial ones, because in marine systems predators are always larger than their prey, whereas in terrestrial systems prey, especially mammalian prey, can be as large or larger than their predators.

As with any edited collection, the individual chapters vary widely in both theme and quality. One important subtheme in this collection is the question of the impact of humans upon populations of marine mammal carnivores. Some of the papers in this collection are written by adherents to ideas developed by Brown University anthropologist Shepherd Krech. These individuals, principally Hildebrandt and Jones, follow a tradition established by Krech, who became famous (or notorious) for his 1999 book, The Ecological Indian, which argued that the Native peoples of North America were not "good ecologists" and may have had significant negative impacts on wildlife populations. This book became quite controversial in ethnobiological circles (I addressed this topic at length in Chapter 8 of my 2011 book, Indigenous Knowledge, Ecology, and Evolutionary Biology).

As a result, there is a range of opinions concerning possible negative impacts of indigenous hunting of pinnipeds. The pinniped species involved are four species of otariid pinniped: the Steller sea lion (Eumetopias jubatus Schreber Otariidae), northern fur seal (Callorbinus ursinus Linnaeus Otariidae), California sea lion (Zalophus californianus Lesson Otariidae), and Guadalupe fur seal (Arctocephalus townsendi Merriam Otariidae). The book's authors discuss two phocid pinnipeds: harbor seal (Phoca vitulina Linnaeus Phocidae) and northern elephant seal (Mirounga angustirostris Gill Phocidae). The Pacific walrus (Odobenus rosmarus divergens Linnaeus Odobenidae) is also a species of interest. As an undergraduate and larval graduate student I participated in studies involving all of these species but the Guadalupe fur seal and the Pacific walrus, working on Southeast Farallon, Año Nuevo, and Santa Barbara Islands, and the Monterey Bay area in general. Handling and observing these species gives me some insight into the experiences involved in hunting such creatures without the benefit of firearms.

Most of these species are strongly sexually dimorphic, with males weighing from 300 (northern fur seal) to $2000 \mathrm{~kg}$ (northern elephant seal). This means that there is potential for a lot of meat, but it also suggests that there is potential danger in taking on large and aggressive males, who are most vulnerable, but also at their most dangerous, during breeding seasons, which occur during spring and early summer 
in the otariids and December through February in northern elephant seal. This winter breeding season also means that winter seas must be dealt with to exploit elephant seals, so it is not surprising that elephant seals, especially males, are the species taken least often as reported in the studies in this collection. The species taken least often after northern elephant seal is Steller sea lion, where the males can weigh up to a ton, which makes them one of the largest carnivores that ever lived. They have teeth the size of grizzly bears, a protective thick mane which gives them their name, plus they are very aggressive towards humans: an "experiment" conducted by some of my colleagues on Año Nuevo using a human dummy resulted in the dummy being thrown into the ocean and torn apart by a bull Steller sea lion, after which everyone became much more cautious around male Steller sea lions.

Another factor that must be considered is the role of climate change and accompanying variation in environmental conditions over historical time. Some of the studies in this collection, e.g. Hill (Chapter 3) and Crockford and Frederick, (Chapter 4) describe hunting regimes associated with ice cover, which came down as far as the Aleutians during the last 5000 years. At ice maxima this would have prevented northern fur seal from breeding on the Pribilof Islands, which are their major breeding colonies today, because they would have been ice choked, even in midsummer, during the Neoglacial period (47002500 ybp).

Hill's chapter is the only contribution that addresses exploitation of walrus. Its major finding is that peoples of the Bering Strait area probably exploited walrus preferentially over bowhead whales for much of the last thousand years, and that whaling may have arisen largely as a response to declines in walrus populations. Evidence of contemporary whaling in the western Arctic is found primarily in areas that seemed to have previously been most dependent upon walrus. This finding may have profound impacts upon the future hunting patterns of these peoples, because both walrus and bowheads (along with ringed seals and bearded seals [Erignathus barbatus Erxleben Phocidae]) are strongly ice dependent, and may no longer be available to indigenous populations as Arctic ice retreats under current conditions of climate change.

Crockford, the senior author of Chapter 4, has become a controversial figure, considered to be a climate change denier in Canada. This seems to be primarily because as an archaeologist, she believes that climates change constantly and that current variations might be considered natural variation in global conditions. This approach can be seen in her chapter where she argues that colder climates resulted in a major expansion of sea ice in the North Pacific and Bering Sea; that altered conditions led to changes in distribution and life history features of pagophilic pinnipeds; and that more temperate pinniped species, like sea lions and fur seals, were effectively excluded from this environment for a considerable period of time, which in turn had a major impact on patterns of human exploitation during this period.

A more comprehensive approach to studying exploitation patterns between humans and pinnipeds is shown in Chapters 5 and 6 by Betts, Meschner, and Lech, who examine a 4500 year time series of otariid and sea otter take on an island in the western Gulf of Alaska in relation to both climate change and human activities. I found this to be one of the most interesting articles, even though the authors have a tendency to present graphs using straight lines to connect data points, e.g., from 2500 to 1750 to $590 \mathrm{BC}$ as if conditions changed at a constant rate between those widely separated dates. Despite this issue with data presentation, the authors present a credible interpretation, i.e., that a combination of climatic variation and human exploitation on both the local and metapopulation level explain the observed fluctuations, which over a period of two thousand years evolved into a sort of natural predator-prey equilibrium. They argue that human predation does have significant impact upon otariid populations. Unlike the concepts developed by the Krech/Martin school of over exploitation and use of blitzkrieg metaphors, however, these scholars argue that pinnipeds quickly developed significant behavioral responses that allowed them to minimize negative impacts. In addition, it appears that exploitation increased when population sizes increased in response to colder, more productive conditions, and declined during warmer, less productive conditions, which is what would be expected from a natural predator-prey dynamic.

In Chapter 5 Betts et al., rely heavily upon methods and concepts developed by R. Lee Lyman, author of the overview of Paleoecological research provided in Chapter 2 of this book. Lyman is critical of the Krechian perspective, arguing that it is hard to 
estimate historical population sizes based solely upon taphonomic remains. He points out that many archaeologists have difficulty identifying marine mammal remains to species level (ancient DNA has apparently been useful in revising earlier assessments). Lyman also points out that few major museums have good collections of marine mammal skeletal material for comparative purposes. For example walrus skeletal material of varying antiquity shows up all over the North Pacific, but that walrus are never found in many of these areas today, so we should be skeptical of modern biogeography when identifying recent remains.

The role of historical biogeography is more important than is generally realized. For example, the two species of fur seal (northern fur seal and Guadalupe fur seal) show complex histories over the last few centuries and millennia. Northern fur seals are found today primarily in subarctic waters during the breeding season, except for a small breeding population that exists on California's San Miguel Island and may be the relict of a metapopulation that ranged from Alaska to California. Northern fur seal probably consisted of two or more distinct forms, possibly even distinct species: the current northern population and a second "species" that ranged from coastal Washington southward. The Guadalupe fur seal, as implied by its name, until recently was found breeding exclusively south of the U. S.-Mexico border, however historically it ranged at least as far north as the Farallon Islands (25 miles west of San Francisco) where it was extirpated by Euroamerican sealers in the $1^{\text {th }}$ century (Busch 1987), and Lyman reports archaeological specimens from as far north as coastal Washington.

The basic structure of the book after Lyman's chapter is to move down the coast from Alaska and the Bering Sea through coastal Canada and then down the Pacific coast of the US from Washington to California's Channel islands, although there is a large gap in that southern and southeastern Alaska and northern British Columbia are not covered at all. For example the cultures of Haida Gwai are not even mentioned, although these may represent the most intact First Nations cultures along the entire coast and could thus provide considerable insight into historical phenomena. These gaps create some interesting complications, because not all of the investigators use the same approaches or come from the same philosophical perspectives. In a way this makes the book more compelling because it does not really come to any obvious consensus.

As one example, some of the authors make periodic stabs at applying optimal foraging theory, usually in that odd way that anthropologists employ concepts from behavioral ecology. In chapter 6, which has the same authors as Chapter 5, but in different order, they make the argument that, "The prey choice model predicts that as the availability of large bodied taxa decline, predation of smaller bodied and lower-ranked taxa increases" (p. 111). What goes unacknowledged is that this theorem was developed after watching great tits choose mealworms of various sizes off a conveyer belt. This means that search and handling times were not assessed, which suggests it may not be applicable as to whether human foragers preferentially select $300-1000 \mathrm{~kg}$ otariids as opposed to $100 \mathrm{~kg}$ phocids or $30 \mathrm{~kg}$ sea otters as food.

Although this point may seem trivial, it is crucial to understanding the Krech-influenced mindset, because individuals adhering to such beliefs employ models from optimal foraging theory to explain how indigenous hunters are not typical predators and are thus, according to their thinking, not ecologically conservationist (Pierotti 2011). In the organisms under study in this collection, sea otters are the least palatable, being mustelids, but sea lions and fur seals represent much more formidable prey, with teeth and jaws the size and strength of their ursid relatives, especially in the case of Steller sea lions. Thus, many indigenous hunters probably concentrated on the medium sized, sexually monomorphic phocids, such as ringed seals (Pusa hispida Schreber Phocidae) and harbor seals which are less aggressive and dangerous than otariids and more palatable than otters.

A more profitable approach is in the use of isotopic analysis, which can reveal whether food is primarily obtained from terrestrial or marine environments, where carbon/nitrogen ratios are markedly different. Interestingly several of these studies reveal that humans, especially in British Columbia were taking primarily terrestrial prey (deer, moose, etc.) even though they lived in a coastal environment (Chapter 7 by McKechnie and Wigan). This chapter is dominated by a ten page table that allows the reader to assess the data in considerable detail. From this table and accompanying figures it is clear that pinnipeds and otters (they include river otters as marine prey) were important prey items only on the outer coast of Vancouver Island, and that most of these 
were smaller species like harbor seals, northern fur seals, and otters. The authors do not include cetaceans, which may have been an important food source in this area. One of their most compelling findings is that as Europeans invaded their ranges, the First Nations peoples apparently abandoned taking marine mammals. This could be either because their own populations were decimated by disease or because of European exploitation patterns, which extirpated populations of fur seals and sea otters.

Moss and Losey (Chapter 8) examine human exploitation of the same set of species in the estuaries of Southern Washington and Northern Oregon. These authors critique the use of optimal foraging theory models, pointing out that size alone may not be an important component of prey choice, especially when accessibility is factored in. This is a more sophisticated use of optimal foraging theory, which incorporates search and handling times into prey selection. They point out that harbor seals, although relatively small (100-150 kg), are the most consistently available prey, being year-round residents that use regular haulouts, and that they are slow on land. Sea otters are also year-round residents. These two species make up the preponderance of the prey taken in these areas. One interesting aspect of this chapter is that they also assess the availability of various species of fishes, which were probably a more important component of overall diet of indigenous peoples.

Chapter 9 by Whitaker and Hildebrandt is equivocal, seeming to want to both critique and endorse the Krechian perspective. Their data suggest that early human hunters had little impact upon the fur seal populations in Northern California that were subsequently extirpated by Europeans, but they close by contending that this was because exploitation of fur seals was an example of "prestige economy", in which males were taken preferentially because this conferred higher status on the hunters who took males primarily so their teeth could be used in necklaces, as opposed to being a conservation tactic in which females in a highly polygynous species were not exploited because of management strategies to maintain high population numbers.

Hildebrandt and his regular co-author Jones (primary author of Chapter 11) are the primary Krech disciples represented in this collection. These two coauthored a 1992 study where they argued that indigenous Californians created a "tragedy of the commons" that led to over exploitation of pinniped populations, even though there is little evidence that a collapse of these populations ever took place. Hildebrandt showed a similar ambivalence in a volume of decidedly Krechian cast (Kay and Simmons 2002) where he argued that, even though Aboriginal hunters had eliminated mainland rookeries of pinnipeds, they may not have had much of a negative impact because of the ability of these populations to establish offshore rookeries that were harder to access. This of course ignores that possibility that the main problem for mainland rookeries may have been the presence of wolves and grizzly bears, which were themselves extirpated after the arrival of European invaders in the 1600s. This means that recent evidence of mainland breeding colonies may not be related to human exploitation. This is typical of the Krechian approach in which Aboriginal human exploitation is to blame for any identified problem while ignoring 1) the presence and possible impacts of nonhuman predators, and 2) that any evidence of "overexploitation" is played up, even when there is no evidence of a population decline of the exploited prey (White 2000; Pierotti 2011).

Gifford-Gonzalez (Chapter 10) assesses the history of fur seals around Central California, including Monterey Bay, arguing that these populations were probably established because the breeding colonies in the Bering Sea and surrounding waters may not have been available during the Neoglacial as discussed by Crockford et al. above. This suggests that the disappearance of these colonies may have been related to climatic factors, rather than human exploitation. She also points out that even though there is evidence of Aboriginal exploitation, especially on Año Nuevo Island, which was connected to the mainland until at least the 19th century, the world metapopulation of this species seem to have been quite stable over the last few thousand years. Only the advent of the European and Japanese sealing industries led to complete extirpation of populations until the establishment of the North Pacific Fur Seal Commission.

In Chapter 11, Jones et al. review the prehistory of the southern sea otter, a subspecies that was almost completely extirpated by Europeans starting with the Russian fur trade in the 1600s. As noted above, Jones was Hildebrandt's co-author on the 1992 paper and the paper in Kay and Simmons (2002). As a Krech disciple, he shows a similarly equivocal view of the role of Aboriginal exploitation, arguing that even 
though hunting of sea otters, especially females, was intense, that it did not depress populations to such a degree that subsequent commercial exploitation by Europeans was precluded.

In the final two chapters, the editors summarize and comment on the data based chapters. In the penultimate chapter (12), they collaborate with the pinniped biologist Bob DeLong, who brings considerable knowledge of the behavior and ecology of these mammals to the discussion. I regard this chapter as a model of interdisciplinary work, where archaeologists and marine mammal ecologists work together to produce genuine insights into long term processes. This chapter emphasizes that pre-contact human hunting did impact marine mammal populations, especially in driving rookeries to offshore islands, which are less accessible to humans, even though they make it clear that pinniped populations on San Miguel Island have remained large until recent commercial exploitation by European invaders, despite continued hunting pressure over the last ten thousand years. This provides little support for the Krechian "tragedy of the commons" argued by Hildebrandt, in fact Hildebrandt's own chapter (9) demonstrates that northern fur seal populations did not decline during this period.

Another point made in Chapter 12 is that the predominant species found in middens throughout much of the Channel Islands are Guadalupe fur seal, which today are the only species that is found year round in these islands. Other supposedly vulnerable species, like northern elephant seal, are found only rarely and may represent scavenging events. This is important, because as DeLong points out, northern elephant seal weanlings are left unprotected by adults for several months following the breeding season from February through May, yet they are not found in large numbers in the archaeological sites.

In the final chapter (13) the editors summarize the results of this symposium in relation to a set of questions they posed in the opening chapter. This allows them to address the points of contention without being openly critical, even though it may be inferred that they do not think that Holocene exploitation had serious negative impacts upon marine mammal populations, except for some local impacts and possibly forcing rookeries onto smaller less accessible islands and rocks. They never address the grizzly bear-wolf issue, which also could have forced rookeries and haulouts offshore. The overall consensus is that a complex mix of human impacts and climate/environmental changes have shaped marine carnivore populations along the Pacific Coast of North America over the last several millennia. Once European invaders arrived, there was a precipitous decline in all of these species, with extirpation of sea otters and Guadalupe fur seal from many areas. Thus, the implication in my estimation is that archaeologists should not assume that human hunting is the primary driver of changes in prehistoric marine mammal population sizes and habitat use patterns.

In a way, this comes down to an issue raised in the last few pages of the book, i.e., that archaeological data do not provide the same detailed insights into previous environments and population dynamics that ecological investigations can provide into contemporary ecological and exploitation systems. This volume shows that this should not prevent interdisciplinary approaches where scholars from different disciplines can provide information that is relevant to interpreting the processes involved in human and nonhuman interactions.

\section{References Cited}

Busch, B. C. 1987. The War Against the Seals: A History of the North American Seal Fishery. McGill-Queens' University Press, Montreal.

Kay, C.E. and R.T. Simmons, eds. 2002. Wilderness and Political Ecology: Aboriginal Influences and the Original State of Nature. University of Utah Press, Salt Lake City.

Krech, S. III. 1999. The Ecological Indian: Myth and History. W. W. Norton and Co., New York.

Pierotti, R. 2011. Indigenous Knowledge, Ecology and Evolutionary Biology. Routledge, Taylor and Francis Group, New York \& London. 